TITLE:

\title{
Preparation of stem cell aggregates with gelatin microspheres to enhance biological functions.
}

$\operatorname{AUTHOR}(S)$ :

Hayashi, Kentaro; Tabata, Yasuhiko

CITATION:

Hayashi, Kentaro ...[et al]. Preparation of stem cell aggregates with gelatin microspheres to enhance biological functions.. Acta biomaterialia 2011, 7(7): 2797-2803

ISSUE DATE:

2011-07

URL:

http://hdl.handle.net/2433/159460

RIGHT:

(c) 2011 Acta Materialia Inc. Published by Elsevier Ltd.; This is not the published version. Please cite only the published version.; この論文は 出版社版でありません。引用の際には出版社版をご確認ご利用くださ い。 
Preparation of stem cell aggregates with gelatin microspheres to enhance biological functions

KENTARO HAYASHI and YASUHIKO TABATA

Short / Running Title: Stem cell aggregates containing microspheres

Department of Biomaterials, Institute for Frontier Medical Sciences, Kyoto University,

53 Kawara-cho Shogoin, Sakyo-ku Kyoto 606-8507, Japan

TEL +81-75-751-4121

FAX $\quad+81-75-751-4646$

E-mail: yasuhiko@frontier.kyoto-u.ac.jp 


\section{Abstract}

The objective of this study is to improve the viability and osteogenic differentiation of rat bone marrow-derived mesenchymal stem cells (MSC) cultured by use of gelatin hydrogel microspheres. Gelatin was dehydrothermally crosslinked at $140{ }^{\circ} \mathrm{C}$ for $48 \mathrm{hr}$ in a water-in-oil emulsion state. When cultured with the gelatin hydrogel microspheres in the round U-bottom well of 96-well multiplates coated poly(vinyl alcohol), MSC formed an aggregate incorporating microspheres homogeneously. The viability of cell aggregate was significantly high compared with that of aggregates formed without microspheres. The MSC proliferation in the aggregates depended on the number and the diameter of microspheres incorporated. Higher MSC proliferation was observed for the aggregates incorporating higher number of larger gelatin microspheres. When evaluated as a measure of aerobic glycolysis, the ratio of L-lactic acid production/ glucose consumption of MSC was significantly lower for MSC cultured with gelatin microspheres than those without microspheres. The MSC production of alkaline phosphatase (ALP) and sulfated glycosaminaglycan (sGAG) was examined to evaluate their potential osteogenic and chondrogenic differentiation. The amount of ALP produced was significantly higher for MSC aggregates cultured with the gelatin microspheres than that of MSC cultured without microspheres. On the other hand, the amount of sGAG produced was significantly lower for MSC aggregates containing the microspheres. It is concluded that the incorporation of gelatin hydrogel microspheres prevents the MSC aggregates from the lack of oxygen, resulting in enhanced vitality of MSC aggregation and the consequent 
promotion of cells proliferation and osteogenic differentiation.

Keywords: mesenchymal stem cell, aggregate, gelatin microspheres, proliferation, osteogenic differentiation 


\section{Introduction}

With the recent advent of stem cell biology, various stem cells have been available and basic cell researches have become more and more popular to make clear the molecular mechanism of cell proliferation and differentiation. Most of cells is required to form an aggregate where the cell-cell interaction is physiologically promoted for the enhancement of cell survival and functions.[1] For example, embryonic stem cells are generally aggregated to form an embryoid body and consequently, initiate to differentiate into different cell lineages.[2] The aggregation of liver cells to form the spheroid is necessary to enhance the metabolic activity.[3] Cell aggregates produced the proteins of extracellular matrix more efficiently than single cells in the separate form.[4] Looking at the cell structure of body tissue, such as the liver and bone, the cell aggregate functions as the minimum unit of formation.[5] Taken together, the aggregation can manipulate the cell-cell interaction, resulting in enhanced biological formations of cells. The conventional cell culture has been performed in the 2-dimensional system, which is quite different from the local environment of cells in the living tissue. Therefore, some technologies to culture cells in the 3-dimensional fashion have been performed.[6-9] However, when the size of cell aggregates becomes larger, the cells inside the aggregate tend to die because of the lack of oxygen and nutrients. $[10,11]$ Such bad conditions often make it practically difficult to perform the in vitro cell culture for a long time period although the long-term culture is required for the basic research of cell differentiation and organization. 
Gelatin is one of the biodegradable biomaterials which have been extensively used for the medical, pharmaceutical, and cosmetic applications. The biosafety has been proven through the long-term practical usage.[12] Hydrogels with different shapes could be formulated and their feasibility as the cell culture substrate[13-15] and cell scaffold for tissue regeneration[16-20] or the release carrier of growth factors and drugs[21-28] have been experimentally demonstrated. Gelatin microspheres were effective in enhancing growth factor-induced tissue regeneration.[29-31] Based on the biological availability and the easiness of hydrogel formulation, in this study, gelatin was selected as the hydrogel material.

The objective of this research is to obtain fundamental information whether or not the incorporation of microspheres into cell aggregates can affect the viability and functions of cells present in the aggregates. To this end, hydrogel microspheres were incorporated into the aggregates of rat bone marrow-derived mesenchymal stem cells (MSC) to positively affect the conditions of oxygen and nutrients. The surface of cell culture plate was coated with poly(vinyl alcohol) to prevent the cell adhesion onto the plate. Consequently, cells can be naturally interacted with each other to form the aggregates efficiently. During the cell culture, gelatin microspheres were co-cultured to allow them to incorporate into the cell aggregates for better supply nutrients and oxygen to cells in the aggregates. The viability of MSC aggregates incorporating gelatin microspheres was evaluated and compared with that of cell aggregates formed without microspheres. We examine the osteogenic and chondrogenic differentiation of MSC aggregates. 


\section{Materials and Methods}

\subsection{Preparation of gelatin hydrogel microspheres}

Gelatin microspheres were prepared by the chemical cross-linking of gelatin in a water-in-oil emulsion state according to the method previously reported.[32] Briefly, aqueous solution $(20 \mathrm{ml})$ of $10 \mathrm{wt} \%$ gelatin (the isoelectric point $=5.0$, the weight-averaged molecular weight $=100,000$, Nitta Gelatin Inc., Osaka, Japan) was preheated at $40{ }^{\circ} \mathrm{C}$, and then added dropwise into $600 \mathrm{ml}$ of olive oil (Wako, Ltd., Osaka, Japan) at $40{ }^{\circ} \mathrm{C}$, followed by stirring at 200 or $400 \mathrm{rpm}$ for $10 \mathrm{~min}$ to prepare a water-in-oil emulsion. The emulsion temperature was decreased to $4{ }^{\circ} \mathrm{C}$ for the natural gelation of gelatin solution to obtain non-crosslinked microspheres. The resulting microspheres were washed three times with cold acetone by combination with centrifugation $\left(5,000 \mathrm{rpm}, 4{ }^{\circ} \mathrm{C}, 5 \mathrm{~min}\right)$ to exclude residual oil completely. Then, they were fractionated in size by sieves with apertures of 20, 32, and $53 \mu \mathrm{m}$ (Iida Seisakusyo, Ltd., Osaka, Japan) and air-dried at $4{ }^{\circ} \mathrm{C}$. The non-crosslinked and dried gelatin microspheres $(200 \mathrm{mg})$ were treated in a vacuum oven at $140{ }^{\circ} \mathrm{C}$ and 0.1 torr for dehydrothermal crosslinking of gelatin according to the method previously reported.[24] The photographs of gelatin hydrogel microspheres in the water-swollen state were taken on the microscope (CKX41, OLYMPUS, Co., Tokyo, Japan). The size of 100 microspheres per each sample was measured by the Image $J$ of computer program (NIH, Bethesda, USA) while the average diameter was calculated from the data. 


\subsection{MSC Preparation}

MSC were prepared from the bone marrow of 3-week-old, male Fischer F344 rats

(Shimizu Laboratory Supply, Kyoto, Japan) according to the conventional procedure.[33] Briefly, both the ends of rat femurs were cut away from the epiphysis, and the bone marrow was flushed out using a syringe (21 gauge needle) with $1 \mathrm{ml}$ of $10 \mathrm{mM}$ phosphate-buffered saline solution (PBS, $\mathrm{pH}$ 7.4). The cell suspension was placed into two $25 \mathrm{~cm}^{2}$ flasks (Iwaki Glass, Ltd., Chiba, Japan) by 4 $\mathrm{ml}$ of alpha minimum essential medium ( $\alpha$ MEM) (Invitrogen, Co., California, USA) supplemented with 15 vol\% fetal calf serum (FCS) (Thermo Inc., Waltham, USA), penicillin (50 U/ml), and streptomycin $(50 \mathrm{U} / \mathrm{ml})$ (standard medium) and cultured at $37{ }^{\circ} \mathrm{C}$ in a $95 \%$ air-5\% carbon dioxide atmosphere. The medium was exchanged on day 3 after culture and every 3 days thereafter. When became sub-confluent, 7 to 10 days culture later, the cells were detached by treatment with PBS containing $0.25 \mathrm{wt} \%$ trypsin and $0.02 \mathrm{wt} \%$ ethylenediaminetetraacetic acid for $5 \mathrm{~min}$ at $37^{\circ} \mathrm{C}$. The cells were subcultured at a density of $2 \times 10^{4}$ cells $/ \mathrm{cm}^{2}$. When proliferated to reach a sub-confluence state, cells were used for the following experiments. This was approved and performed according to guidelines of Institute for Frontier Medical Sciences, Kyoto University.

\subsection{Preparation of cell non-adhesion surface}

Various types of poly(vinyl alcohol), kindly supplied from Unichika Co., Tokyo, Japan, 
(Table 1) were dissolved in PBS (1 wt $\%)$. The solution $(500 \mu \mathrm{l} /$ well) was added in each well of 24-well multiplate and incubated at $37{ }^{\circ} \mathrm{C}$ for $15 \mathrm{~min}$. Then, the solution was removed by aspirator and the well was washed with PBS $(500 \mu 1 /$ well $)$ twice. The MSC suspension $\left(4 \times 10^{4}\right.$ cells $/ \mathrm{ml}, 500$ $\mu \mathrm{l} /$ well) was placed into the well plate. After $4 \mathrm{hr}$ incubation, the number of cells present in the medium was determined by the fluorometric DNA assay according to the method reported previously[34]. Briefly, cells were carefully washed with PBS 3 times to collect, and stored at $-30{ }^{\circ} \mathrm{C}$ until to assay. After thawing, the cells were digested in $30 \mathrm{mM}$ sodium citrate-buffered saline solution ( $\mathrm{pH} 7.4, \mathrm{SCS})$ containing proteinase $\mathrm{K}(250 \mu \mathrm{g} / \mathrm{ml})$ and dodecyl sulfate $(0.2 \mathrm{mg} / \mathrm{ml})$ at $65{ }^{\circ} \mathrm{C}$ for $12 \mathrm{hr}$. After the cell sample solution $(100 \mu \mathrm{l})$ was mixed with $100 \mu \mathrm{l}$ of SCS containing $1 \mathrm{mg} / \mathrm{ml}$ Hoechst 33258 dye, the fluorescence intensity of the mixed solution was measured on a fluorescence spectrometer (SPECTRA MAX GEMINI EM, Molecular Devices, Sunnyvale CA) at excitation and emission wavelengths of 355 and $460 \mathrm{~nm}$, respectively. The cell number was obtained by use of the calibration curve which had been prepared with cell suspension at determined numbers. Experiments were performed for 3 wells of each sample unless otherwise mentioned. Then, the number ratio of cells non-adhered to those adhered to the PVA-coated well was calculated.

\subsection{Preparation of MSC aggregates with or without gelatin microspheres incorporation}

PVA with a polymerization degree of 1,800 and percent saponification of 88 mole $\%$, was 
dissolved in PBS (1 wt\%). This solution (100 $\mu \mathrm{l} /$ well) was added into each well of 96-well multiplate with a flat bottom or round bottom (U-bottom) and incubated at $37{ }^{\circ} \mathrm{C}$ for $15 \mathrm{~min}$. Then, the solution was removed by aspiration and the well was washed with PBS (100 $\mu 1 /$ well $)$ twice. Gelatin microspheres of $17.6 \pm 7.4,47.9 \pm 22.2$, and $106.8 \pm 17.8 \mu \mathrm{m}$ in diameter and MSC were suspended in the standard medium separately. The suspension of gelatin microspheres $\left(0,2 \times 10^{3}\right.$, $2 \times 10^{4}, 2 \times 10^{5}$, and $2 \times 10^{6}, 50 \mu \mathrm{l} /$ well) was added into the well coated, and then the MSC suspension $\left(2 \times 10^{4}\right.$ cells $/ \mathrm{ml}, 50 \mu \mathrm{l} /$ well $)$ was placed and cultured. Experiments were performed for 3 wells of each sample unless otherwise mentioned.

\subsection{Preparation of cell aggregate frozen section}

MSC $\left(1 \times 10^{4} /\right.$ well $)$ were cultured with $1 \times 10^{4}$ gelatin microspheres $(17.6 \pm 7.4 \mu \mathrm{m}$ in diameter) to form the cell aggregate. After incubation for 7 days, the aggregate was fixed with $4 \%$ paraformaldehyde at $4{ }^{\circ} \mathrm{C}$ for $1 \mathrm{hr}$ and embedded with an Optimal Cutting Temperature (O. C. T.) compound (Sakura Finetek Japan Co., Ltd., Japan) and freezed by liquid nitrogen. The frozen sections were prepared by cryotome (CM3050S, Leica, Germany) and stained with TO-PRO-3 (Molecular Probes, Oregon, USA) together with hematoxylin. The section of $10 \mu \mathrm{m}$ thickness was viewed by confocal laser scanning microscopy.

\subsection{Measurement of live cells number}


The number of live cells in MSC aggregates with or without gelatin microspheres was determined by counting the number of cell nuclei after crystal violet treatment.[35] Briefly, mixed solution of $0.2 \mathrm{M}$ citric acid and $0.2 \mathrm{wt} \%$ crystal violet was added (100 $\mu \mathrm{l} /$ well) to each well of the well plate 2, 4, and 7 days after MSC culture (the number of cells seeded initially per well $=1 \times 10^{3}$ and $1 \times 10^{4}$ ) with or without $1 \times 10^{2}, 1 \times 10^{3}$, and $1 \times 10^{4}$ gelatin microspheres of $17.6 \pm 7.4,47.9 \pm 22.2$, and $106.8 \pm 17.8 \mu \mathrm{m}$ in diameter. After the crystal violet staining, the cells were lysed in $0.1 \mathrm{wt} \%$ Triton X-100 solution in PBS at $37{ }^{\circ} \mathrm{C}$ overnight to extract the nuclei from the cells. After pipetting, the number of nuclei collected was viewed on a microscope (CKX31-11PHP, OLYMPUS, Co., Tokyo, Japan) and counted on a hema-cytometer (OneCell Inc. Japan). The nucleus shape of live cells is generally round, which is different from the irregular shape of dead cells nuclei. The live cells can be distinguished from the dead cells by their nucleus shape. As controls, MSC were cultured on each well of 96-well multiplate with flat bottom at a density of $1 \times 10^{3}$ cells/well. Experiments were performed for 3 wells of each sample unless otherwise mentioned.

\subsection{Measurement of metabolic activity}

MSC were cultured with gelatin microspheres in the similar way to form the cell aggregation. The number of cells seeded initially per well is $1 \times 10^{3}$. The number of gelatin microspheres with different diameters of $17.6 \pm 7.4,47.9 \pm 22.2$, and $106.8 \pm 17.8 \mu \mathrm{m}$ is $1 \times 10^{4}$.

The amount of glucose consumed by MSC aggregates was determined by measuring the 
change in glucose concentration in the culture medium with glutest Neo super (Sanwa kagaku kenkyusyo Co., Ltd., Japan) 2, 4, and 7 days after incubation. Similarly, the amount of L-lactic acid produced by MSC aggregates was determined by E-kit (R-Biopharm AG Co., Ltd., Germany) 2, 4, and 7 days after incubation. On the other hand, the number of live cells was determined by the crystal violet staining described above, while the amount of L-lactic acid produced per the number of live cells was calculated. As a measure to evaluate the metabolic activity of cells, the L-lactic acid / glucose ratio was calculated.[35] Experiments were performed for 3 wells of each sample unless otherwise mentioned.

2.8. Differentiation evaluation of MSC aggregates with or without gelatin microspheres incorporation

The cell culture to form the aggregate was performed similarly. The cell aggregates were cultured for 7 days in the osteogenic differentiation medium of $\alpha M E M$ containing 10 $\mathrm{mM} \beta$-glycerophosphate, $0.2 \mathrm{mM}$ L-ascorbic acid 2-phosphate (Sigma Ltd., Poole, UK), $10 \mathrm{nM}$ dexamethasone, and $10 \mathrm{vol} \%$ fetal bovine serum. The number of gelatin microspheres used is 0 , $1 \times 10^{3}$, and $1 \times 10^{4}$. As a control, MSC were cultured on each well of 96-well multiplate with flat bottom at a density $1 \times 10^{4}$ cells/well. To evaluate the osteogenic differentiation, the amount of alkaline phosphatase (ALP) produced from MSC was determined by the Lab assay ALP kit (Wako, Ltd., Osaka, Japan) according to the procedure reported previously.[36, 37] Experiments were 
performed for 3 wells of each sample unless otherwise mentioned.

The culture medium of chondrogenic differentiation was DMEM containing $1 \mathrm{mM}$ sodium pyruvate (Lonza, Tokyo, Japan), 100 nM dexamethasone, 1 vol\% ITS PREMIX (Becton, Dickinson and Company), 0.35 mM L-proline, 0.2 mM L-ascorbic acid 2-phosphate (Sigma Ltd., Poole, UK), and $10 \mathrm{ng} / \mathrm{ml}$ transforming growth factor (TGF)- $\beta 1$. The time periods of chondrogenic culture were 7, 14, and 21 days. The number of gelatin microspheres used is 0 and $1 \times 10^{4}$. For chondrogenic differentiation, the amount of sulphated glycosaminoglycans (sGAG) produced from MSC cultured with or without gelatin microspheres was determined by the dimethylmethylene blue dye (DMMB) assay previously reported.[37] The cell culture medium (25 $\mu \mathrm{l})$ obtained was mixed with $225 \mu \mathrm{l}$ of DMMB solution. Then, the solution absorbance was measured at $525 \mathrm{~nm}$ using a VERSAmax multiplate reader (Molecular Devices, Sunnyvale CA). The content of sGAG produced was calculated from the absorbance by a calibration curve prepared by use of known amounts of chondroitin sulfate. Experiments were performed for 3 wells of each sample unless otherwise mentioned.

\subsection{Statistical analysis}

All the statistical data are expressed as the mean \pm standard error of the mean (SEM). The data was analyzed by the unpaired ANOVA to determine the statistical differences between the two mean values and the significant difference was accepted to be the $P$-value of $<0.05$. 


\section{Results}

\subsection{Characterization of gelatin hydrogel microspheres}

Figure 1 shows the typical microscopic pictures of gelatin hydrogel microspheres. The microspheres were of spherical shape and had a smooth surface. The size of microspheres in the swollen condition was $17.6 \pm 7.4,47.9 \pm 22.2$, and $106.8 \pm 17.8 \mu \mathrm{m}$.

\subsection{Preparation of non adhesion surface by PVA coating}

Figure 2 shows the non-adhesion behavior of MSC on culture plates coated with different types of PVA. The cell adhesion was inhibited by coating with PVA with higher degrees of polymerization and lower percentages of saponification.

\subsection{Preparation of MSC aggregates with or without gelatin microspheres incorporation}

Figure 3 shows the microscopic pictures of MSC $24 \mathrm{hr}$ after incubation with or without gelatin microspheres in flat bottom or U-bottom. MSC aggregates were formed only for the U-bottom culture dish, in remarked contrast to the flat one.

Figure 4 shows the confocal laser scanning microscopic pictures of MSC aggregates 7 days after incubation with gelatin microspheres. MSC and microspheres seemed to be distributed homogeneously in the MSC aggregate. The similar condition was observed for the microspheres of 
different sizes (data not shown).

\subsection{Cell viability of MSC aggregates with or without gelatin microspheres incorporation}

Figure 5 shows the time profiles of live MSC number in cell aggregates after culture in the presence or absence of different numbers of gelatin microspheres with various sizes. The number of live cells in the MSC aggregates with gelatin microspheres increased with time whereas that of MSC aggregates without microspheres did not. As the number of gelatin microspheres became larger, the number of live cells increased. The larger number of live cells was observed for gelatin microspheres with larger sizes. For the microspheres with $106.8 \pm 17.8 \mu \mathrm{m}$ at the cell number of 1 $\times 10^{4}$ /well, the number of live cells was larger than that of monolayer culture after 7 days incubation.

\subsection{Metabolic functions of MSC aggregates with or without gelatin microspheres incorporation}

Figure 6A shows the glucose consumption of MSC aggregates cultured with or without gelatin microspheres. MSC aggregates with gelatin microspheres consumed the larger amount of glucose than those without gelatin microspheres. The consumption glucose for cell aggregate with larger microspheres incorporation was similar to that of monolayer cell culture.

Figure 6B shows the L-lactic acid production of cell aggregates cultured with or without gelatin microspheres. MSC aggregates cultured with gelatin microspheres produced the amount of 
L-lactic acid less than those without gelatin microspheres. The L-lactic acid production for the cell aggregates cultured with gelatin microspheres was similar to that of MSC monolayer culture.

Figure 6C shows the time profiles of metabolic activity of MSC aggregates containing gelatin microspheres $\left(1 \times 10^{3} /\right.$ well). The L-lactic acid/ glucose ratio of MSC aggregates cultured with gelatin microspheres was significantly lower than that of microspheres-free aggregates and similar to that of MSC monolayer.

\subsection{Osteogenic and chondrogenic of MSC aggregates}

Figure 7A shows the ALP production of MSC aggregates cultured with or without different numbers of gelatin microspheres. MSC aggregates with gelatin microspheres produced more ALP than MSC in the monolayer culture. No ALP production was observed for MSC aggregates without microspheres.

Figure 7B shows the sGAG production of MSC aggregates with or without gelatin microspheres. MSC aggregates with gelatin microspheres produced less sGAG than MSC aggregates without gelatin microspheres 21 days after incubation.

\section{Discussion}

The cell adhesion was inhibited efficiently by PVA coating although the extent depended on the PVA type (Figure 2). The reason can be explained in terms of PVA adsorption onto the culture 
plate of polystyrene. PVA with lower saponification degrees has more units of vinyl acetate residues than that with higher degrees. It is possible that the higher unit number makes PVA molecules more hydrophobic, resulting in enhanced PVA adsorption onto the plate through the hydrophobic interaction. The hydrophilicity of PVA is enhanced with an increase in the degree of PVA polymerization. This would increase the hydrophilicity of plate surface and consequently decrease the cell adhesion. There have been several research reports on the effect of surface hydrophobicity on the cell adhesion.[38-45] Generally, less cell adhesion was observed on the surface of culture plate with higher hydrophilicity. It is necessary for efficient formation of MSC aggregates to modify the bottom shape of culture plate in addition to the surface hydrophilicity by the PVA coating (Figure 3). It is likely that the U-shape bottom allowed cells to put together to the center of well. As the result, the frequency of cell-cell contact would increase, resulting in promoted formation of MSC aggregates. For the flat-bottom plate, although the formation of cell aggregates was observed randomly and heterogeneously, the efficiency was very low. This is due to less frequency of cell-cell contact. Although cells do not adhere onto the surface of PVA-coated substrates, it is likely that less frequency of cell-cell contact on the flat surface of substrate does not result in the efficient formation of cell aggregates.

When MSC were cultured together with gelatin microspheres, the aggregates were formed. However, the aggregate formation depended on the size and amount of microspheres used. When the amount of microspheres was excessive, MSC aggregates were not formed (the number of cells 
seeded initially per well $=1 \times 10^{5} /$ well) even 7 days after incubation (data not shown). This can be explained in terms of cell-cell interaction. It is reported that the cell-cell contact is one of the factors contributing to the regulation of cell differentiation.[46] It is highly conceivable that the presence of microspheres at an excessive amount physically suppresses the cell-cell contact and interaction, resulting in suppressed formation of cell aggregates. Considering the mechanism of cell aggregate formation, the natural cell-cell interaction is essential. The interaction to form cell aggregates will be achieved only in the presence of microspheres with an appropriate size range at the optimal amount.

Higher glucose levels and lower L-lactic acid production were observed for MSC aggregates formed in the presence of gelatin microspheres. The ratio of L-lactic acid to glucose is a general measure of aerobic metabolism.[35] The lower the ratio is, the higher the aerobic metabolism is. It is apparent in Figure 6, the ratio of cell aggregates with microspheres was significantly lower than that of aggregates without microspheres. The ratio was similar to that of monolayer culture where oxygen is generally abundant in cell culture. It is highly conceivable that the presence of microspheres in the cell aggregates gives cells the better condition of oxygen, resulting in the lower ratio of L-lactic acid/ glucose, in other words, the achievement of an aerobic condition of cell culture. In addition, the presence of microspheres distributed in the cell aggregate would increase the oxygen permeability inside the aggregate. Taken together, we can say with certainly that the number of live cells proliferated in the cell aggregate containing microspheres became higher. 
The ALP activity of cell aggregates as one measure of osteogenic differentiation was enhanced (Figure 7A), but oppositely chondrogenic differentiation was suppressed (Figure 7B). It is well recognized that MSC are likely to differentiate into osteogenic lineages at the normal oxygen level, whereas they are differentiated into chondrocytes at the lower oxygen level.[47-49] For MSC aggregates containing gelatin microspheres, it is possible that the oxygen in the aggregate is at the normal level. On the contrary, MSC aggregates without gelatin microspheres are in a lower oxygen condition because of restricted oxygen permeation. The homogeneous presence of microspheres in cell aggregates would keep the inner oxygen level normal, resulting in promoted osteogenic differentiation of MSC. On the contrary, it is possible that the cell aggregate without microspheres is in an ischemic condition, which tends to allow cells to differentiate into chondrocytes. The amount of sGAG production depended on the incubation time. The reason of time dependence is not clear at present.

Better osteogenesis of MSC for cell aggregates containing microspheres than those in the monolayer culture can be explained from the viewpoint of cell interaction. In the cell aggregate, cells interact in a 3-dimensional manner of natural cell-cell contact whereas cells monolayer cultured interact in a 2-dimensional one. It is highly conceivable that the $3 \mathrm{D}$ interaction of natural system gives cells better conditions for osteogenesis.

Stem cell aggregates incorporating microspheres containing transforming growth factor (TGF) - $\beta 1$ have been designed to demonstrate their enhanced chondrogenesis.[34, 50, 51] These 
papers experimentally confirm that the cell aggregation and combined TGF- $\beta 1$ release were effective in inducing the chondrogenic differentiation of cells in vitro. The 3-dimensional cell-cell interaction in the aggregates would enable cells to communicate to each other in the natural fashion, resulting in enhanced activity of TGF- $\beta 1$ for chondrogenesis. In this study, the similar positive effect of microspheres incorporation on the culture condition of cells in the aggregates was observed and the metabolic activity of cells was significantly improved. However, the cell differentiation cannot be compared directly because the microspheres used in this study do not contain any growth factors and the mixing method or ratio of microspheres and cells was different. In future, gelatin microspheres containing growth factor will be used and incorporated into the cell aggregates to evaluate the cell differentiation.

The present study demonstrates that the incorporation of gelatin hydrogel microspheres in the MSC aggregates was effective in enhancing the cell viability of aggregates and their metabolic activity. The microspheres enabled MSC in the aggregates to significantly enhance the glucose consumption and decrease the L-lactic acid/glucose ratio of aerobic measure, which implies the improvement of biological condition of oxygen and nutrient inside the aggregates. The better metabolic condition may affect the osteogenic and chondrogenic differentiation of MSC in the aggregates. However, the cell differentiation of aggregates with or without microspheres incorporation should be investigated more clearly in terms of histological, biochemical, and immunohistochemical examinations. 


\section{Conclusions}

The objective of this study is to improve the viability and osteogenic differentiation of MSC cultured by use of gelatin hydrogel microspheres. When cultured with the gelatin hydrogel microspheres in the round U-bottom well of 96-well multiplates coated poly(vinyl alcohol), MSC formed an aggregate incorporating microspheres homogeneously. The viability of cell aggregate was significantly high compared with that of aggregates formed without microspheres. Higher MSC proliferation was observed for the aggregates incorporating higher number of larger gelatin microspheres. When evaluated as a measure of aerobic glycolysis, the ratio of L-lactic acid production/glucose consumption of MSC was significantly lower for MSC cultured with gelatin microspheres than those without microspheres. It is concluded that the incorporation of gelatin hydrogel microspheres prevents the MSC aggregates from the lack of oxygen, resulting in enhanced vitality of MSC aggregation and the consequent promotion of cells proliferation and osteogenic differentiation. 


\section{References}

1. Kurosawa H. Methods for inducing embryoid body formation: in vitro differentiation system of embryonic stem cells. J Biosci Bioeng 2007;103:389-398.

2. Fukuda J, Sakai Y, Nakazawa K. Novel hepatocyte culture system developed using microfabrication and collagen/polyethylene glycol microcontact printing. Biomaterials 2006;27:1061-1070.

3. Rodriguez-Enriquez S, Gallardo-Perez JC, Aviles-Salas A, Marin-Hernandez A, Carreno-Fuentes L, Maldonado-Lagunas V, et al. Energy metabolism transition in multi-cellular human tumor spheroids. J Cell Physiol 2008;216:189-197.

4. Lin RZ, Chang HY. Recent advances in three-dimensional multicellular spheroid culture for biomedical research. Biotechnol J 2008;3:1172-1184.

5. Nelson LJ, Walker SW, Hayes PC, Plevris JN. Low-Shear Modelled Microgravity Environment Maintains Morphology and Differentiated Functionality of Primary Porcine Hepatocyte Cultures. Cells Tissues Organs 2010.

6. Okochi M, Takano S, Isaji Y, Senga T, Hamaguchi M, Honda H. Three-dimensional cell culture array using magnetic force-based cell patterning for analysis of invasive capacity of BALB/3T3/v-src. Lab Chip 2009;9:3378-3384.

7. Mohan N, Nair PD, Tabata Y. A 3D biodegradable protein based matrix for cartilage tissue engineering and stem cell differentiation to cartilage. J Mater Sci Mater Med 2009;20 Suppl 1:S49-60.

8. Benton G, George J, Kleinman HK, Arnaoutova IP. Advancing science and technology via 3D culture on basement membrane matrix. J Cell Physiol 2009;221:18-25.

9. Hanjaya-Putra D, Gerecht S. Vascular engineering using human embryonic stem cells. Biotechnol Prog 2009;25:2-9.

10. Kellner K, Liebsch G, Klimant I, Wolfbeis OS, Blunk T, Schulz MB, et al. Determination of oxygen gradients in engineered tissue using a fluorescent sensor. Biotechnol Bioeng 2002;80:73-83.

11. Malda J, Klein TJ, Upton Z. The roles of hypoxia in the in vitro engineering of tissues. Tissue Eng 2007;13:2153-2162.

12. Zekorn D. Intravascular retention, dispersal, excretion and break-down of gelatin plasma substitutes. Bibl Haematol 1969;33:131-140.

13. Narita A, Takahara M, Ogino T, Fukushima S, Kimura Y, Tabata Y. Effect of gelatin hydrogel incorporating fibroblast growth factor 2 on human meniscal cells in an organ culture model. Knee 2009;16:285-289.

14. Takahashi Y, Yamamoto M, Tabata Y. Osteogenic differentiation of mesenchymal stem cells in biodegradable sponges composed of gelatin and beta-tricalcium phosphate. Biomaterials 2005;26:3587-3596.

15. Hori Y, Inoue S, Hirano Y, Tabata Y. Effect of culture substrates and fibroblast growth factor addition on the proliferation and differentiation of rat bone marrow stromal cells. Tissue Eng 2004;10:995-1005. 
16. Watanabe M, Jo J, Radu A, Kaneko M, Tabata Y, Flake AW. A tissue engineering approach for prenatal closure of myelomeningocele with gelatin sponges incorporating basic fibroblast growth factor. Tissue Eng Part A 2010;16:1645-1655.

17. Akagawa Y, Kubo T, Koretake K, Hayashi K, Doi K, Matsuura A, et al. Initial bone regeneration around fenestrated implants in Beagle dogs using basic fibroblast growth factor-gelatin hydrogel complex with varying biodegradation rates. J Prosthodont Res 2009;53:41-47.

18. Hiraoka Y, Yamashiro H, Yasuda K, Kimura Y, Inamoto T, Tabata Y. In situ regeneration of adipose tissue in rat fat pad by combining a collagen scaffold with gelatin microspheres containing basic fibroblast growth factor. Tissue Eng 2006;12:1475-1487.

19. Igai H, Chang SS, Gotoh M, Yamamoto Y, Misaki N, Okamoto T, et al. Regeneration of canine tracheal cartilage by slow release of basic fibroblast growth factor from gelatin sponge. ASAIO J 2006;52:86-91.

20. Okamoto T, Yamamoto Y, Gotoh M, Huang CL, Nakamura T, Shimizu Y, et al. Slow release of bone morphogenetic protein 2 from a gelatin sponge to promote regeneration of tracheal cartilage in a canine model. J Thorac Cardiovasc Surg 2004;127:329-334.

21. Kimura Y, Tabata Y. Controlled release of stromal-cell-derived factor-1 from gelatin hydrogels enhances angiogenesis. J Biomater Sci Polym Ed 2010;21:37-51.

22. Esaki J, Marui A, Tabata Y, Komeda M. Controlled release systems of angiogenic growth factors for cardiovascular diseases. Expert Opin Drug Deliv 2007;4:635-649.

23. Tabata Y, Nagano A, Ikada Y. Biodegradation of hydrogel carrier incorporating fibroblast growth factor. Tissue Eng 1999;5:127-138.

24. Ozeki M, Tabata Y. In vivo degradability of hydrogels prepared from different gelatins by various cross-linking methods. Journal of biomaterials science 2005;16:549-561.

25. Nitta N, Ohta S, Tanaka T, Takazakura R, Toyama T, Sonoda A, et al. An initial clinical study on the efficacy of cisplatin-releasing gelatin microspheres for metastatic liver tumors. Eur J Radiol 2009;71:519-526.

26. Patel ZS, Yamamoto M, Ueda H, Tabata Y, Mikos AG. Biodegradable gelatin microparticles as delivery systems for the controlled release of bone morphogenetic protein-2. Acta Biomater 2008;4:1126-1138.

27. Kikuchi T, Kubota S, Asaumi K, Kawaki H, Nishida T, Kawata K, et al. Promotion of bone regeneration by CCN2 incorporated into gelatin hydrogel. Tissue Eng Part A 2008;14:1089-1098.

28. Kushibiki T, Tomoshige R, Iwanaga K, Kakemi M, Tabata Y. Controlled release of plasmid DNA from hydrogels prepared from gelatin cationized by different amine compounds. J Control Release 2006;112:249-256.

29. Ichinohe N, Kuboki Y, Tabata Y. Bone regeneration using titanium nonwoven fabrics combined with fgf-2 release from gelatin hydrogel microspheres in rabbit skull defects. Tissue Eng Part A 2008;14:1663-1671.

30. Patel ZS, Ueda H, Yamamoto M, Tabata Y, Mikos AG. In vitro and in vivo release of vascular 
endothelial growth factor from gelatin microparticles and biodegradable composite scaffolds. Pharm Res 2008;25:2370-2378.

31. Tabata Y, Hijikata S, Muniruzzaman M, Ikada Y. Neovascularization effect of biodegradable gelatin microspheres incorporating basic fibroblast growth factor. J Biomater Sci Polym Ed 1999;10:79-94.

32. Tabata Y, Ikada Y, Morimoto K, Katsumata H, Yabuta T, Iwanaga K, et al. Surfactant-free preparation of biodegradable hydrogel microspheres for protein release. Journal of Bioactive and Compatible Polymers 1999;14:371-384.

33. Nagane K, Jo J, Tabata Y. Promoted adipogenesis of rat mesenchymal stem cells by transfection of small interfering RNA complexed with a cationized dextran. Tissue Eng Part A 2010;16:21-31.

34. Ogawa T, Akazawa T, Tabata Y. In vitro proliferation and chondrogenic differentiation of rat bone marrow stem cells cultured with gelatin hydrogel microspheres for TGF-beta1 release. J Biomater Sci Polym Ed 2010;21:609-621.

35. Nam JH, Ermonval M, Sharfstein ST. Cell attachment to microcarriers affects growth, metabolic activity, and culture productivity in bioreactor culture. Biotechnol Prog 2007;23:652-660.

36. Yamamoto M, Takahashi Y, Tabata Y. Controlled release by biodegradable hydrogels enhances the ectopic bone formation of bone morphogenetic protein. Biomaterials 2003;24:4375-4383.

37. Farndale RW, Buttle DJ, Barrett AJ. Improved quantitation and discrimination of sulphated glycosaminoglycans by use of dimethylmethylene blue. Biochim Biophys Acta 1986;883:173-177.

38. Lee JH, Kopecek J, Andrade JD. Protein-resistant surfaces prepared by PEO-containing block copolymer surfactants. J Biomed Mater Res 1989;23:351-368.

39. Nonckreman CJ, Fleith S, Rouxhet PG, Dupont-Gillain CC. Competitive adsorption of fibrinogen and albumin and blood platelet adhesion on surfaces modified with nanoparticles and/or PEO. Colloids Surf B Biointerfaces 2010;77:139-149.

40. Yu Q, Zhang $\mathrm{Y}$, Chen $\mathrm{H}$, Zhou $\mathrm{F}$, Wu Z, Huang $\mathrm{H}$, et al. Protein adsorption and cell adhesion/detachment behavior on dual-responsive silicon surfaces modified with poly(N-isopropylacrylamide)-block-polystyrene copolymer. Langmuir 2010;26:8582-8588.

41. Wei J, Igarashi T, Okumori N, Maetani T, Liu B, Yoshinari M. Influence of surface wettability on competitive protein adsorption and initial attachment of osteoblasts. Biomed Mater 2009;4:045002.

42. Campillo-Fernandez AJ, Unger RE, Peters K, Halstenberg S, Santos M, Salmeron Sanchez M, et al. Analysis of the biological response of endothelial and fibroblast cells cultured on synthetic scaffolds with various hydrophilic/hydrophobic ratios: influence of fibronectin adsorption and conformation. Tissue Eng Part A 2009;15:1331-1341.

43. Ikada Y. Surface modification of polymers for medical applications. Biomaterials 1994;15:725-736.

44. Uyama Y, Kato K, Ikada Y. Surface modification of polymers by grafting. Grafting/Characterization Techniques/Kinetic Modeling 1998;137:1-39.

45. Sun YH, Gombotz WR, Hoffman AS. Synthesis and Characterization of Non-Fouling Polymer Surfaces: I. Radiation Grafting of Hydroxyethyl Methacrylate and Polyethylene Glycol Methacrylate onto Silastic Film. Journal of Bioactive and Compatible Polymers, 1986;1:316-334. 
46. Tang J, Peng R, Ding J. The regulation of stem cell differentiation by cell-cell contact on micropatterned material surfaces. Biomaterials 2010;31:2470-2476.

47. Kanichai M, Ferguson D, Prendergast PJ, Campbell VA. Hypoxia promotes chondrogenesis in rat mesenchymal stem cells: a role for AKT and hypoxia-inducible factor (HIF)-1alpha. J Cell Physiol 2008;216:708-715.

48. Lennon DP, Edmison JM, Caplan AI. Cultivation of rat marrow-derived mesenchymal stem cells in reduced oxygen tension: effects on in vitro and in vivo osteochondrogenesis. $J$ Cell Physiol 2001;187:345-355.

49. Salim A, Nacamuli RP, Morgan EF, Giaccia AJ, Longaker MT. Transient changes in oxygen tension inhibit osteogenic differentiation and Runx2 expression in osteoblasts. J Biol Chem 2004;279:40007-40016.

50. Han Y, Wei Y, Wang S, Song Y. Enhanced chondrogenesis of adipose-derived stem cells by the controlled release of transforming growth factor-beta1 from hybrid microspheres. Gerontology 2009;55:592-599.

51. Han Y, Wei Y, Wang S, Song Y. Cartilage regeneration using adipose-derived stem cells and the controlled-released hybrid microspheres. Joint Bone Spine 2010;77:27-31. 


\section{Figure captions}

Figure 1. Microscopic pictures of gelatin hydrogel microspheres dispersed in water. The microspheres were separated with sieves with diameters ranging below $20 \mu \mathrm{m}$ (A), between 20 and $32 \mu \mathrm{m}(\mathrm{B})$, and between 32 and $53 \mu \mathrm{m}(\mathrm{C})$. The scar bar is $100 \mu \mathrm{m}$ length.

Figure 2. Percentage of cells non-adhered onto culture plates coated with various PVAs: (A) the effect of PVA molecular weight. The degree of saponification is $88 \%$. (B) the effect of PVA saponification. The degree of polymerization is about 1,700 .

Figure 3. Microscopic pictures of MSC $24 \mathrm{hr}$ after incubation with (A, B) or without (C, D) gelatin microspheres with $106.8 \pm 17.8 \mu \mathrm{m}$ in diameter $\left(1 \times 10^{4 / w e l l}\right)$ in flat $(\mathrm{A}, \mathrm{C})$ or U-bottom of

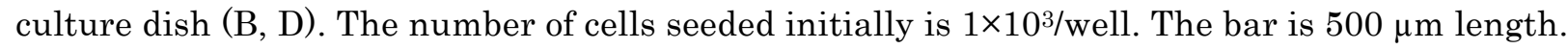

Figure 4. Microscopic pictures of MSC aggregates 7 days after incubation with gelatin microspheres $\left(1 \times 10^{4 / w e l l}\right)$. The diameter of microspheres used is $17.6 \pm 7.4 \mu \mathrm{m}$ : (A) a confocal microscopic picture of cell aggregate stained with the TO-PRO-3, (B) a light microscopic picture of the corresponding cell aggregate, and (C) the merged picture. The scale bar is $100 \mu \mathrm{m}$ length.

Figure 5. The time profiles of live MSC number in cell aggregates after cultured in the absence and presence of different numbers of gelatin microspheres with various sizes $\left(1 \times 10^{3 / w e l l}\right)$.

(A) The cells were cultured with $0(\bigcirc), 1 \times 10^{2}(\Delta), 1 \times 10^{3}(\square)$, and $1 \times 10^{4}(\bullet)$ of gelatin microspheres. The diameter of microspheres used is $106.8 \pm 17.8 \mu \mathrm{m}$. As a monolayer culture, the cells were cultured in each well of flat bottom 96-well multiplates without gelatin microspheres $(\nabla)$. , 
$\mathrm{p}<0.01$; significant against the number of live MSC in cell aggregates cultured without gelatin microspheres at the corresponding time. \#, $p<0.01$; significant against the number of live MSC in cell aggregates cultured with $1 \times 10^{2}$ of gelatin microspheres at the corresponding time. ${ }^{*}, \mathrm{p}<0.01$; significant against the number of live MSC in cell aggregates cultured with $1 \times 10^{3}$ of gelatin microspheres at the corresponding time. $\S, \mathrm{p}<0.01$; significant against the number of live monolayer MSC cultured without gelatin microspheres at the corresponding time.

(B) The cells were cultured with gelatin microspheres of $17.6 \pm 7.4(\mathbf{\Delta}), 47.9 \pm 22.2(\mathbf{\square})$, and 106.8 \pm 17.8 $\mu \mathrm{m}(\bullet)$ in diameter or without gelatin microspheres $(\bigcirc)$. The number of microspheres seeded per well is $1 \times 10^{4}$. As monolayer culture, the cells were cultured in flat bottom 96 -well multiplates without gelatin microspheres $(\nabla) .{ }^{\star}, \mathrm{p}<0.01$; significant against the number of live MSC in cell aggregates cultured without gelatin microspheres at the corresponding time. $\uparrow, p<0.01$; significant against the number of live MSC in cell aggregates cultured with gelatin microspheres of $17.6 \pm 7.4$ $\mu \mathrm{m}$ in diameter at the corresponding time. $\neq, \mathrm{p}<0.01$; significant against the number of live MSC in cell aggregates cultured with gelatin microspheres of $47.9 \pm 22.2 \mu \mathrm{m}$ in diameter at the corresponding time. $\S, \mathrm{p}<0.01$; significant against the number of live monolayer MSC cultured without gelatin microspheres at the corresponding time.

Figure 6. The metabolic activity of MSC aggregates cultured with or without gelatin microspheres and MSC cultured as monolayer. The cells were cultured with gelatin microspheres of $17.6 \pm 7.4(\mathbf{\Delta}), 47.9 \pm 22.2(\mathbf{\bullet})$, and $106.8 \pm 17.8 \mu \mathrm{m}(\bullet)$ in diameter or without gelatin microspheres $(\bigcirc)$. 
The number of microspheres seeded per well is $1 \times 10^{4}$. As monolayer culture, the cells were cultured in flat bottom 96 -well multiplates without gelatin microspheres $(\nabla)$.

(A) The glucose consumption of MSC aggregates cultured with or without gelatin microspheres and MSC cultured as monolayer. ${ }^{\star}, \mathrm{p}<0.05$; significant against the consumption of glucose in conditioned medium of MSC aggregates cultured without gelatin microspheres at the corresponding time. $\dagger$, $\mathrm{p}<0.05$; significant against the consumption of glucose in conditioned medium of MSC aggregates cultured with gelatin microspheres of $17.6 \pm 7.4 \mu \mathrm{m}$ in diameter at the corresponding time. $\neq, \mathrm{p}<0.05$; significant against the consumption of glucose in conditioned medium of MSC aggregates cultured with gelatin microspheres of $47.9 \pm 22.2 \mu \mathrm{m}$ in diameter at the corresponding time.§, $\mathrm{p}<0.05$; significant against the consumption of glucose in conditioned medium of monolayer MSC cultured without gelatin microspheres at the corresponding time.

(B) The L-lactic acid production of live MSC in cell aggregates cultured with or without gelatin microspheres and MSC cultured as monolayer. ${ }^{\star}, \mathrm{p}<0.05$; significant against the production of L-lactic acid in conditioned medium per the number of live MSC in cell aggregates cultured without gelatin microspheres at the corresponding time.

(C) The time profiles of metabolic activity of MSC aggregates containing gelatin microspheres $\left(1 \times 10^{3 / \text { well }) . ~}{ }^{\star}, \mathrm{p}<0.05\right.$; significant against the L-lactic acid / glucose ratio of cell aggregates cultured without gelatin microspheres at the corresponding time.

Figure 7. The differentiation of MSC aggregates with or without gelatin microspheres. 
(A) The amount of ALP produced 7 days after incubation of MSC aggregates with or without gelatin microspheres of $106.8 \pm 17.8 \mu \mathrm{m}$ in diameter in the osteogenic differentiation medium $\left(1 \times 10^{4 / w e l l}\right)$, and monolayer MSC without gelatin microspheres. The number of cells seeded initially per well $=$ $1 \times 10^{4} .^{\star}, \mathrm{p}<0.05$; significant against the amount of ALP produced from MSC aggregates cultured without gelatin microspheres at the corresponding time.

(B) The amount of sGAG produced 7, 14, and 21 days after incubation of MSC aggregates with (•) or without $(\bigcirc)$ gelatin microspheres of $106.8 \pm 17.8 \mu \mathrm{m}$ in diameter in the chondrogenic differentiation

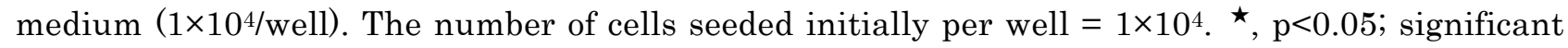
against the amount of sGAG produced from MSC aggregates cultured without gelatin microspheres at the corresponding time. 
(A)

(B)

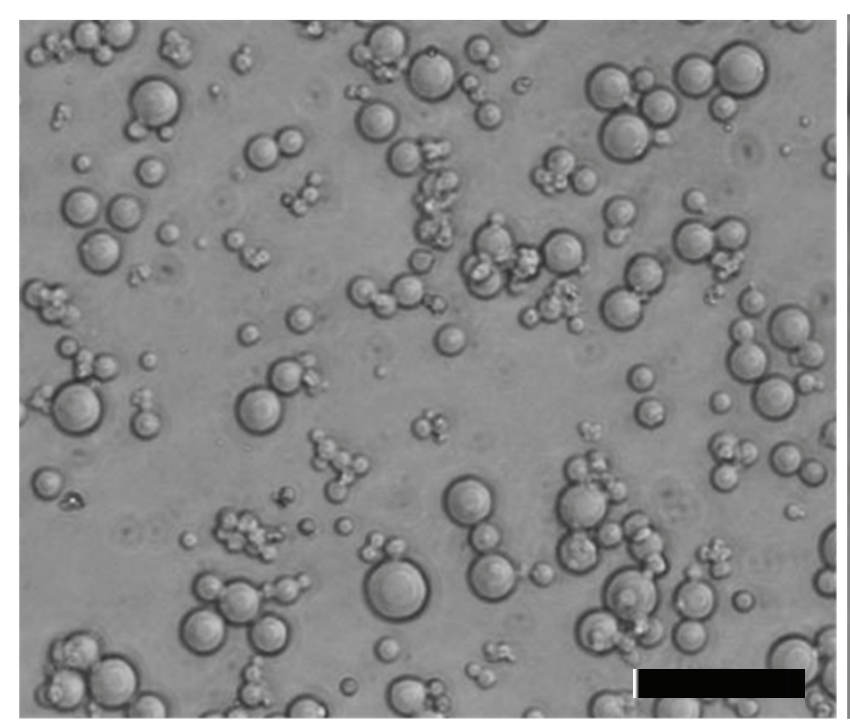

Fig. 1
(C)

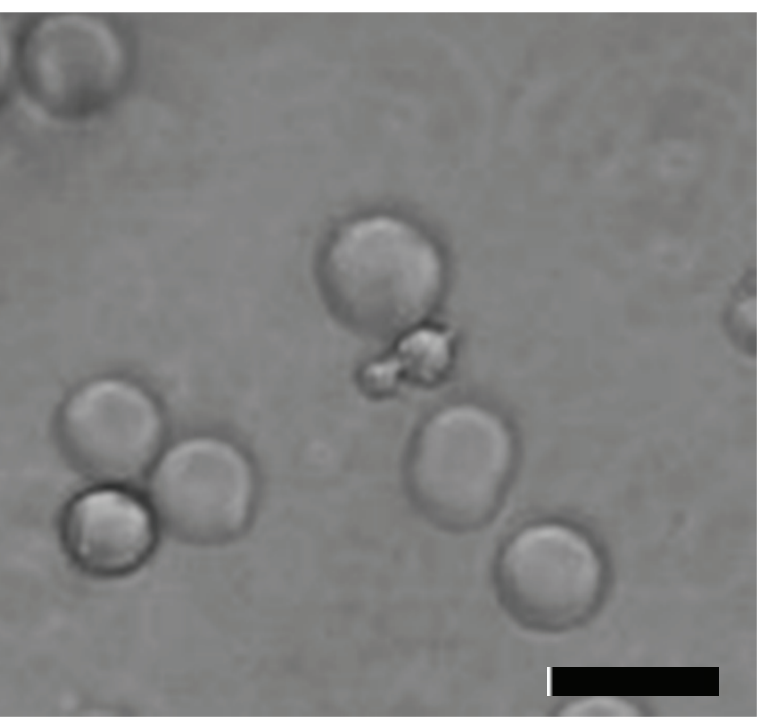

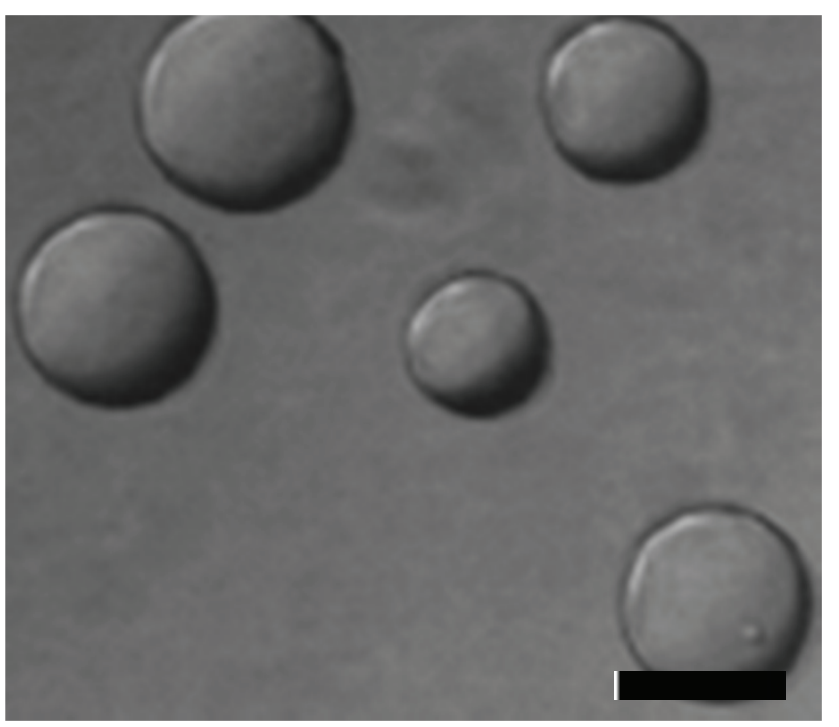


Table 1. Physicochemical properties of PVA coated

\begin{tabular}{cc}
\hline Degree of polymerization & Percentage of saponification $($ mole $\%)$ \\
\hline 500 & 88 \\
1000 & 88 \\
1700 & 96.5 \\
1800 & 88 \\
1800 & 84.5 \\
\hline
\end{tabular}




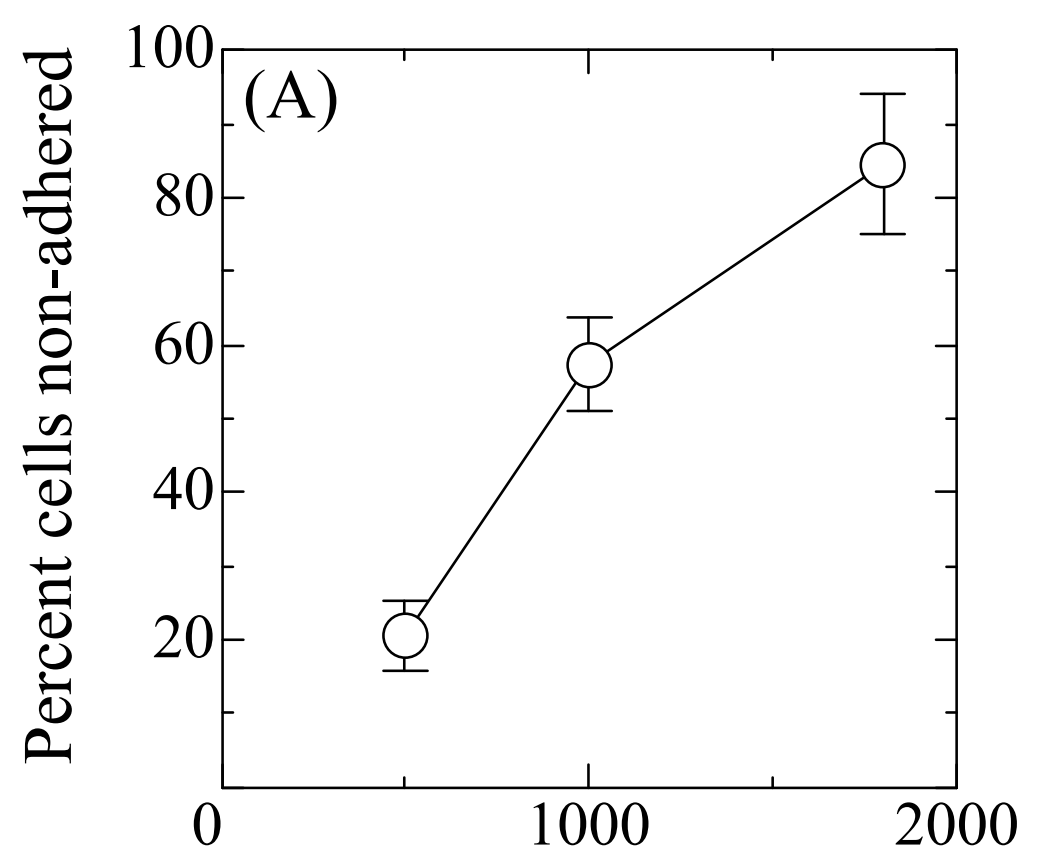

Degree of polymerization

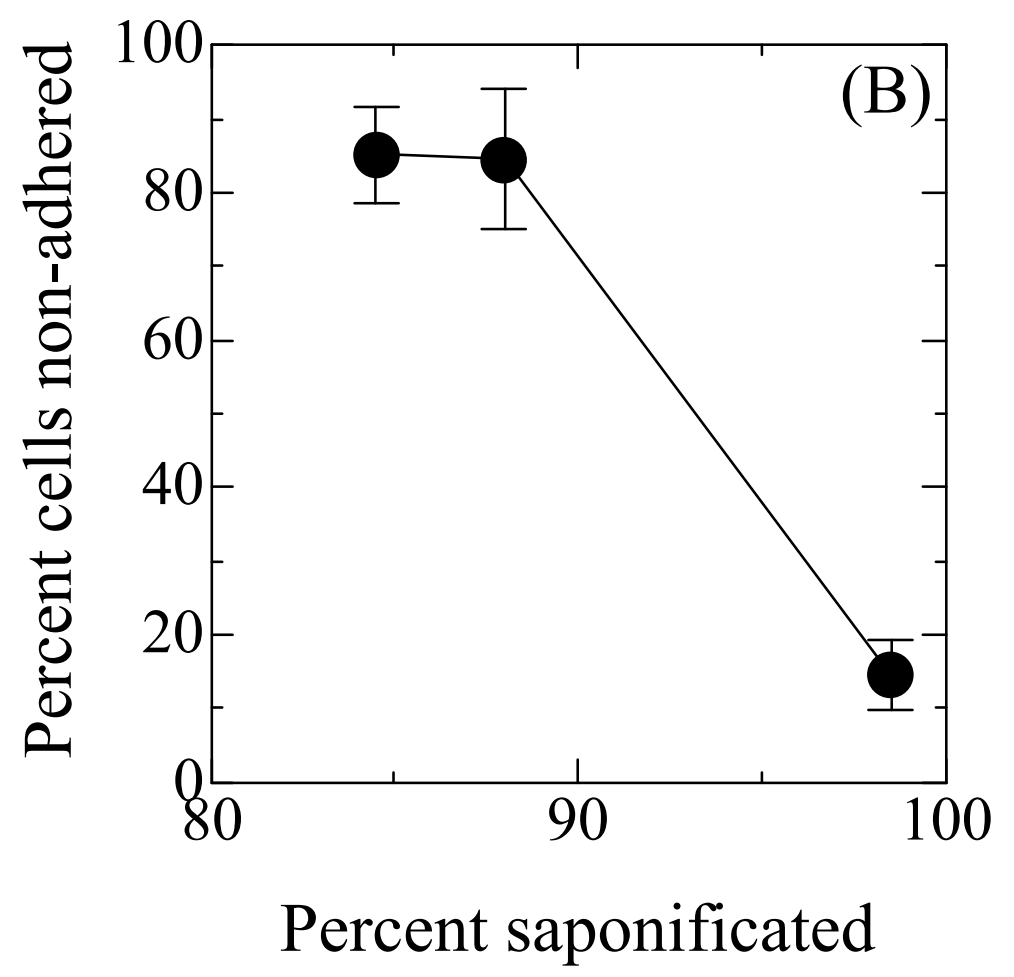

Fig. 2 


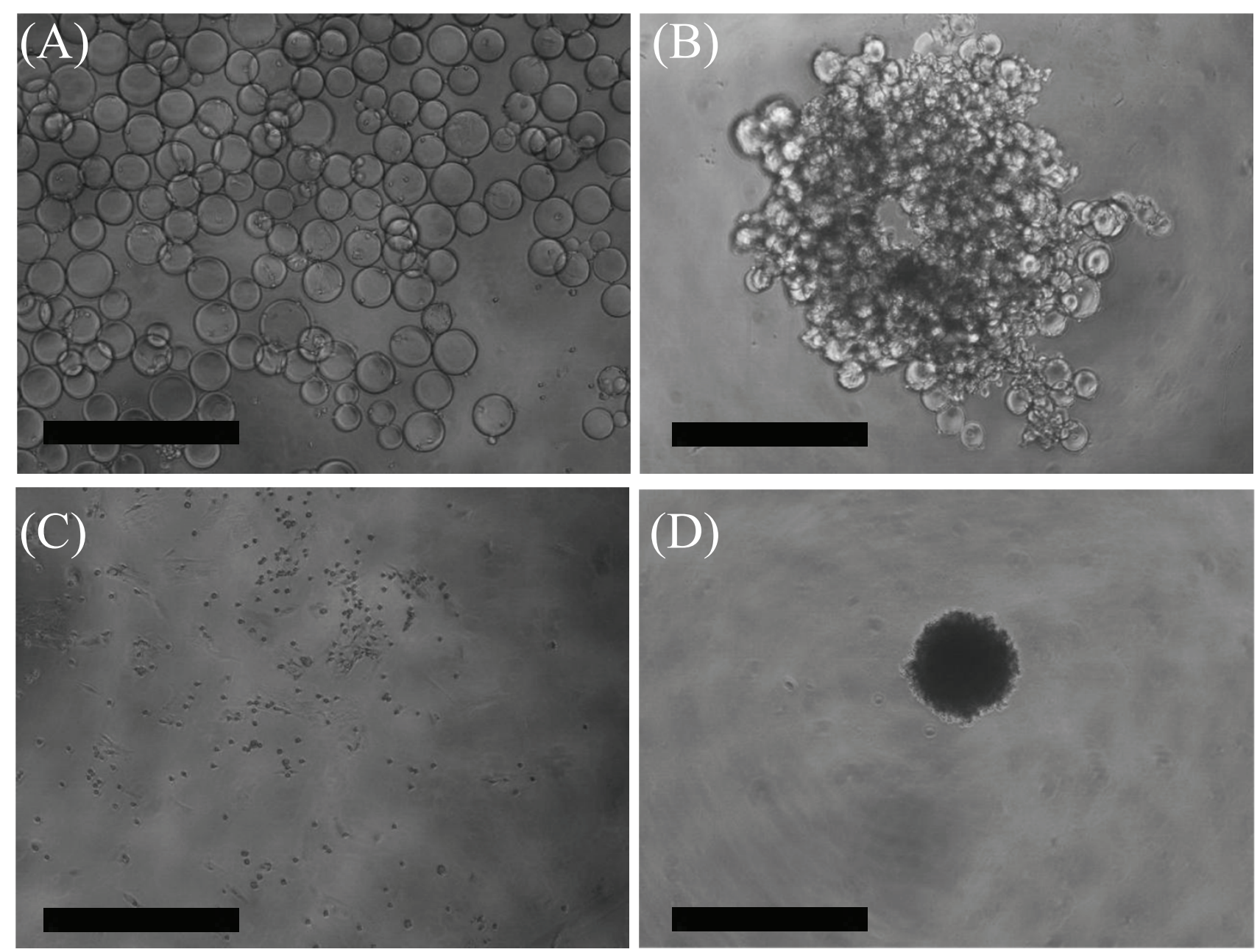

Fig. 3 


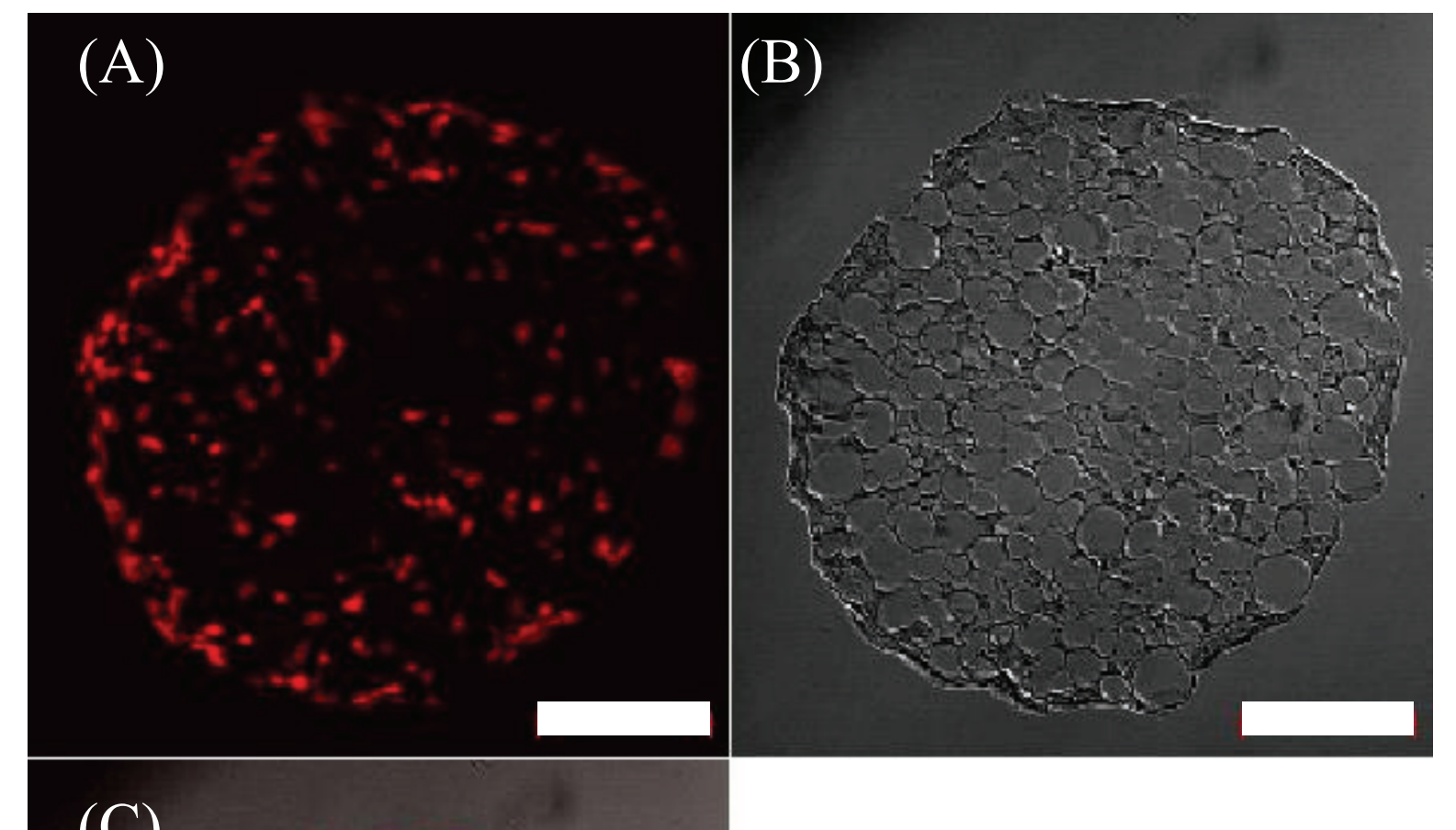

Fig. 4 

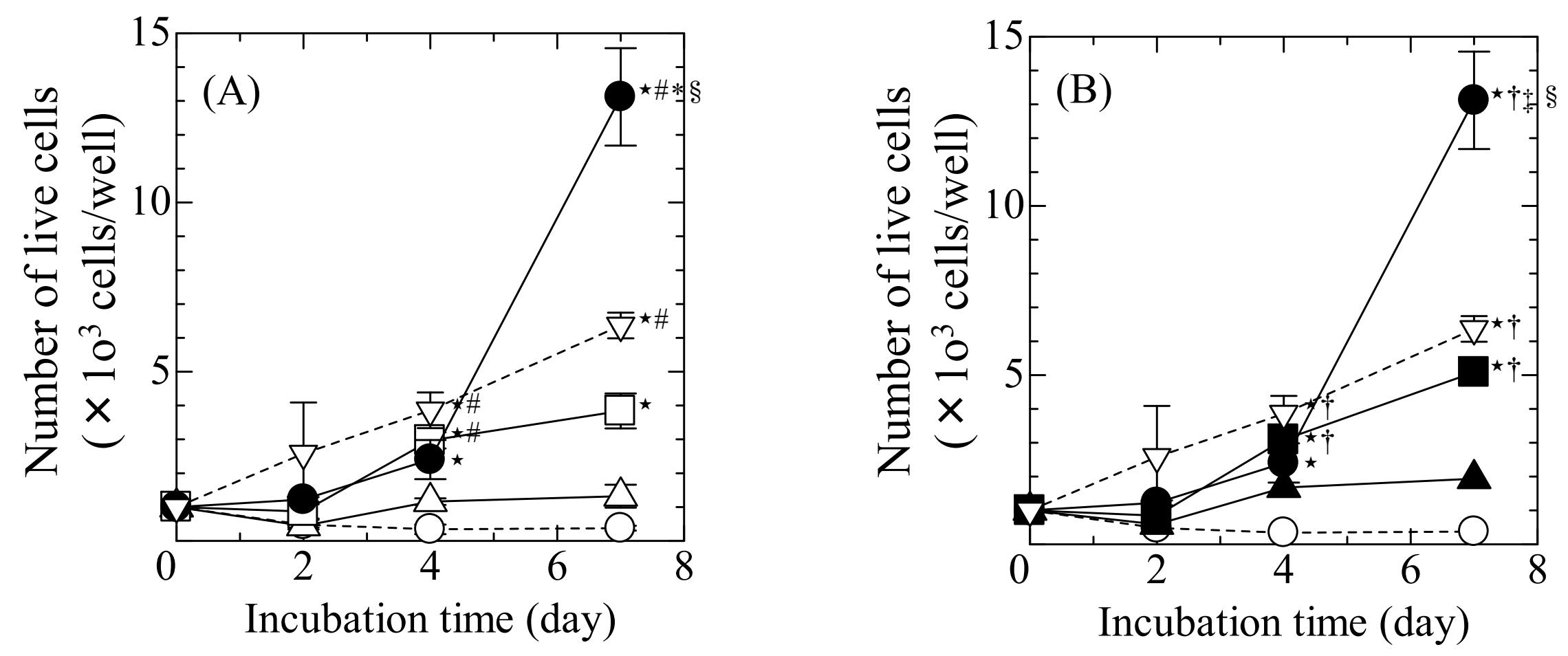

Fig. 5 

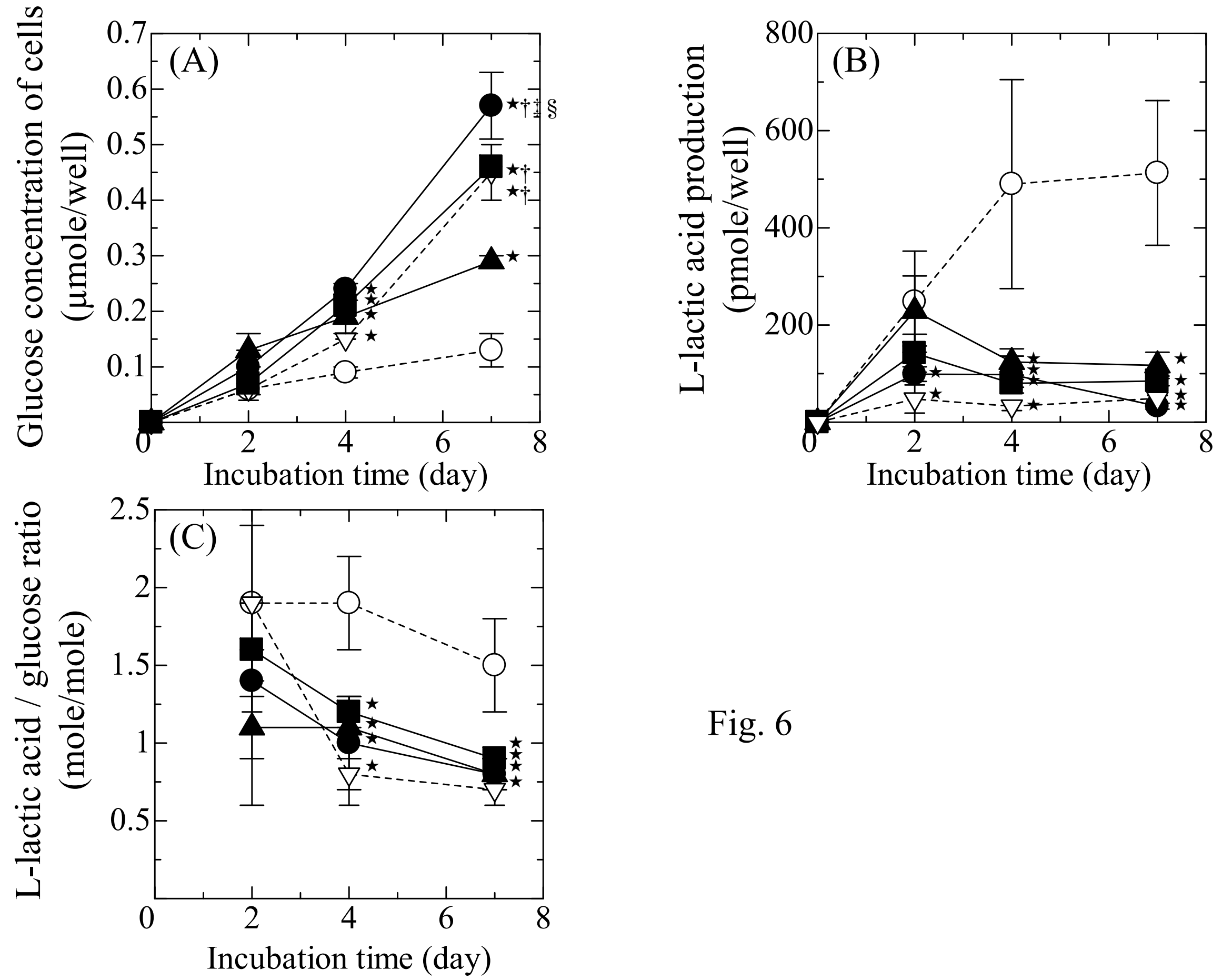

Fig. 6 

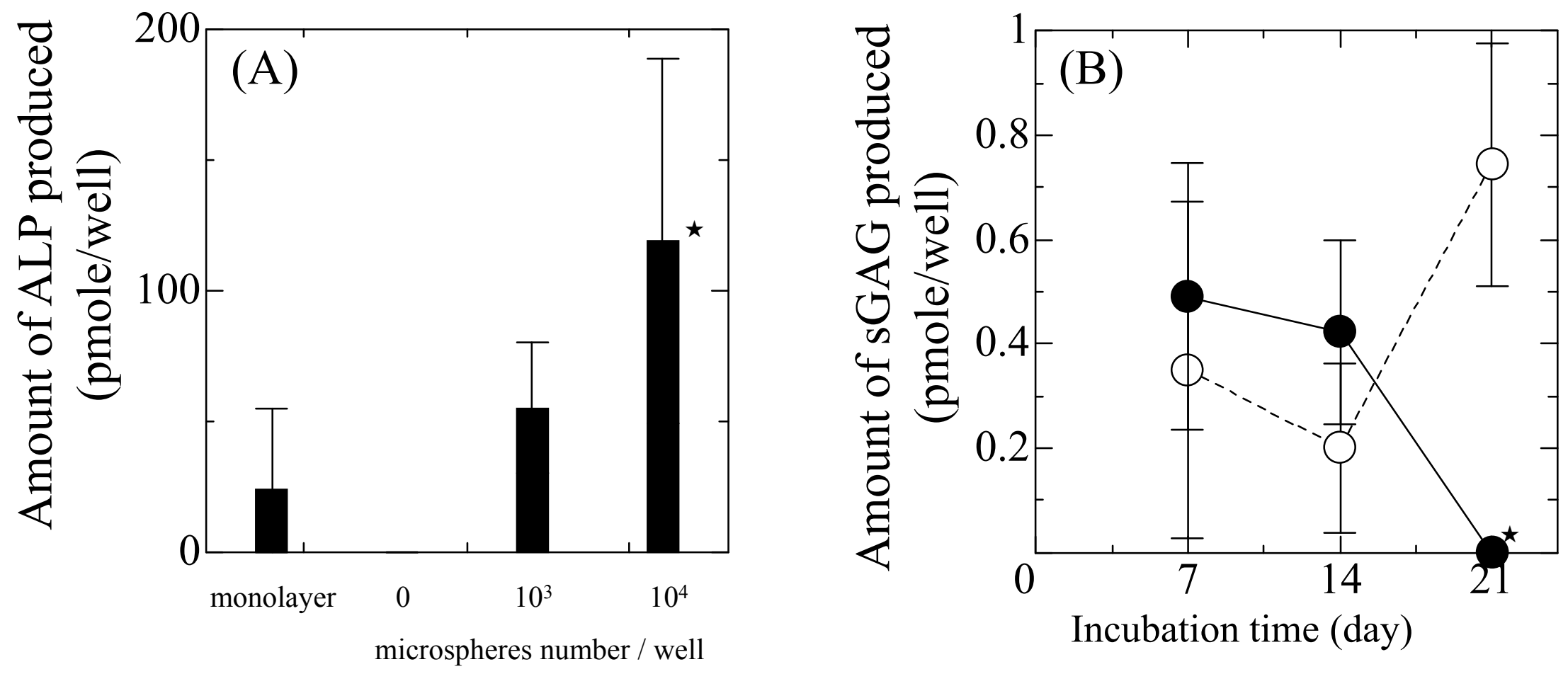

Fig. 7 